\title{
The Effects of Helicobacter pylori Eradication Therapy for Chronic Idiopathic Thrombocytopenic Purpura
}

\author{
Jae Jin Hwang, Dong Ho Lee, Hyuk Yoon, Cheol Min Shin, Young Soo Park, and Nayoung Kim \\ Department of Internal Medicine, Seoul National University Bundang Hospital, Seongnam, Korea
}

\section{See editorial on page 323.}

Background/Aims: The aim of this study was to evaluate the ability of Helicobacter pylori eradication treatment to increase platelet counts in Korean patients with chronic idiopathic thrombocytopenic purpura (ITP). Methods: A total of 102 patients were evaluated against two criteria. First, those diagnosed with $H$. pylori infections in whom eradication was successful were assigned to the $H$. pylori-positive and -eradicated group $(\mathrm{n}=39)$, whereas those diagnosed with $H$. pylori infections in whom eradication failed were assigned to the $H$. pylori-positive and -non-eradicated group $(n=3)$, and those without $H$. pylori infections were assigned to the $H$. pylorinegative group ( $n=60)$. Second, patients with complete remission in whom the platelet recovery effect was maintained over the average follow-up period of 6 months after eradication therapy were defined as the responder group $(n=58)$, whereas those with partial or no response were defined as the nonresponder group $(n=44)$. Results: The platelet counts of the $H$. pylori-positive and -eradicated group were significantly increased 6 months after eradication therapy compared to those of the $H$. pylori-positive and -non-eradicated group and the $H$. pylori-negative group $(43.2 \pm 29.1$ to $155.3 \pm 68.7 \times 10^{3} / \mu \mathrm{L}$ vs $42.5 \pm 28.1$ to $79.8 \pm 59.7 \times 10^{3} / \mu \mathrm{L}$ vs $43.1 \pm 28.9$ to $81.2 \pm 62.2 \times 10^{3} / \mu \mathrm{L} ; \mathrm{p}=0.041$ ). The eradication therapy success rate in the responder group was $100.0 \%$ (39/39), in contrast to the nonresponder group (0\%, 0/3) ( $p<0.001$ ). Conclusions: $H$. pylori eradication therapy was related to increased platelet count, and successful eradication affected the increased platelet count in Korean patients with chronic ITP. (Gut Liver 2016;10:356-361)
Key Words: Helicobacter pylori; Eradication therapy; Purpura, thrombocytopenic, idiopathic; Platelet count

\section{INTRODUCTION}

Helicobacter pylori is a causal factor in gastritis, peptic ulcer, and gastric adenocarcinoma and has a close relationship with the occurrence of mucosal-associated lymphoid tissue lymphoma. ${ }^{1}$ In addition to gastric disorders, $H$. pylori is associated with various non-gastrointestinal-related illnesses such as coronary artery disease, autoimmune disorders, and pernicious anemia. ${ }^{2-4}$ $H$. pylori was recently demonstrated as an etiological factor in idiopathic thrombocytopenic purpura (ITP) in some prospective studies, with reports of platelet numbers increasing in these patients after $H$. pylori eradication treatment. ${ }^{5-7}$ However, other studies have shown a negative result after eradication treatment, with the $H$. pylori infection rate of patients with ITP showing little difference with the infection rate of normal subjects, leading to controversy.

ITP is an acquired blood disorder in which autoantibodies or immune complexes destroy platelets, leading to a decreased platelet count to below the lower limit of the normal range $\left(150 \times 10^{3} / \mu \mathrm{L}\right)$ through which mucocutaneous hemorrhage characteristically occurs. In the treatment of ITP, steroids, $\gamma$ globulin, anti-RhD, splenectomy, immunosuppressive agents, and other similar therapies have been employed to reduce or block autoantibody production. Among these treatment modalities, steroid therapy is considered the most effective; however, if discontinued, most patients experience relapse, with only $10 \%$ to $30 \%$ of total patients maintaining sustained remission. When other treatment methods were used, $64 \%$ of patients reportedly showed increased platelet counts. ${ }^{10}$ If a patient's condition is refractory to conventional treatment methods or treatment side effects such as immunosuppression are observed, keeping the

Correspondence to: Dong Ho Lee

Department of Internal Medicine, Seoul National University Bundang Hospital, 82 Gumi-ro 173beon-gil, Bundang-gu, Seongnam 463-707, Korea

Tel: +82-31-787-7006, Fax: +82-31-787-4051, E-mail: dhljohn@yahoo.co.kr

Received on December 12, 2014. Revised on April 13, 2015. Accepted on May 18, 2015. Published online September 9 , 2015 pISSN 1976-2283 eISSN 2005-1212 http://dx.doi.org/10.5009/gnll4483

(a) This is an Open Access article distributed under the terms of the Creative Commons Attribution Non-Commercial License (http://creativecommons.org/licenses/by-nc/4.0) which permits unrestricted non-commercial use, distribution, and reproduction in any medium, provided the original work is properly cited. 
patient on long-term therapy may be difficult, which creates a demand for treatment methods with fewer side effects. In the case of $H$. pylori eradication therapy, the advantages offered include fewer side effects and shorter treatment duration than conventional therapy.

In this study, the effectiveness of $H$. pylori eradication therapy in patients with ITP patients was assessed in relation to its ability to increase platelet numbers in patients with chronic ITP in Korea.

\section{MATERIALS AND METHODS}

\section{Study population}

This study was conducted in Seoul National University Bundang Hospital between January 2003 and December 2013. The medical records of patients diagnosed with chronic ITP were retrospectively reviewed. The patients selected for the study met the following inclusion criteria: (1) age >18 years; and (2) diagnosis of ITP according to American Society of Hematology criteria based on an initial platelet count $<100 \times 10^{3} / \mu \mathrm{L}$. The exclusion criteria were as follows: (1) age <18 years; (2) thrombocytopenia was related to autoimmune disorders, drugs, a family history consistent with inherited thrombocytopenia, human immunodeficiency virus infection, hepatitis, or pseudothrombocytopenia; (3) previous history of $H$. pylori eradication; and (4) history of medication with proton pump inhibitors, $\mathrm{H}_{2}$ receptor antagonists, or antibiotics in the previous 4 weeks.

\section{Diagnosis of $H$. pylori and eradication therapy}

All participants were tested for the presence of $H$. pylori with a ${ }^{13} \mathrm{C}$-urea breath test. If the result was positive, the patient was diagnosed as having $H$. pylori infection. Patients who were diagnosed with $H$. pylori received standard triple therapy (rabeprazole $20 \mathrm{mg}$ twice a day, amoxicillin 1,000 mg twice a day, and clarithromycin $500 \mathrm{mg}$ twice a day) for 1 week to eradicate $H$. pylori. The results of the eradication therapy were assessed by using a ${ }^{13} \mathrm{C}$-urea breath test 4 weeks after eradication thera- py. Patients without $H$. pylori infection received no eradication therapy. None of the patients received additional concurrent immunosuppressive treatment or prednisolone except for previous maintenance treatment over 6 months during the $H$. pylori eradication therapy and follow-up periods.

\section{Assessment of treatment efficacy}

We evaluated treatment efficacy of the patients with chronic ITP by two criteria. The primary criterion was the increased platelet count according to $H$. pylori infection or eradication success. We divided the patients by three groups. Those diagnosed with $H$. pylori infection who had eradication success after therapy were assigned to the $H$. pylori-positive and -eradicated (HPPE) group; those diagnosed with $H$. pylori infection who had eradication failure after therapy were assigned to the $H$. pyloripositive and -non-eradicated (HPNE) group and those without $H$. pylori infection after initial $H$. pylori assessment were assigned to the $H$. pylori-negative (HPN) group. We evaluated the platelet counts at baseline and 2 and 6 months between the three groups.

The secondary criterion was the increased platelet count according to treatment response. The definition of treatment response was assessed according to the ITP International Working Group guidelines. ${ }^{11}$ Complete remission was determined to have occurred if the platelet count increased to at least $100 \times 10^{3} / \mu \mathrm{L}$ within 2 months of the start of treatment regardless of whether maintenance therapy was ongoing. Partial remission was defined as an increase in platelets to a minimum of $30 \times 10^{3} / \mu \mathrm{L}$ within 2 months of the start of treatment regardless of whether the patient was on maintenance therapy or an increased platelet count to more than twice the number in the pretreatment period. No response was defined as a platelet count that remained below $30 \times 10^{3} / \mu \mathrm{L}$, showed an increase of $<50 \%$ compared with the initial platelet count, or showed no increase. In this study, patients who achieved complete remission and maintained the platelet recovery effect over the average follow-up period evaluated at 6 months after eradication therapy were defined as the

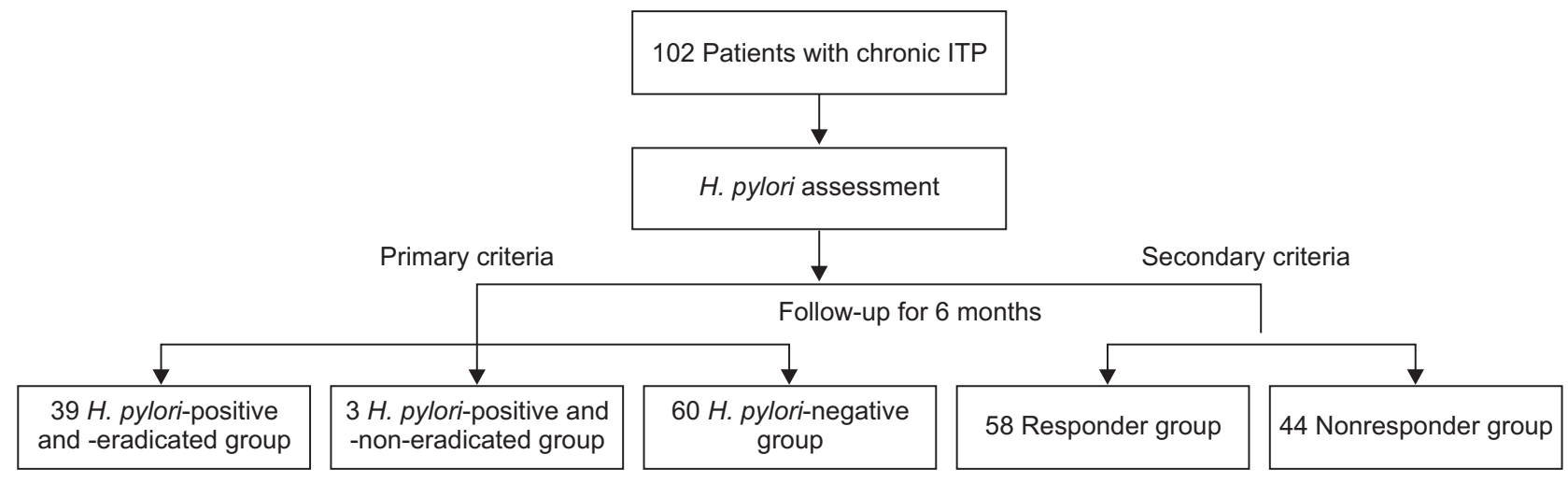

Fig. 1. A schematic diagram of the study.

ITP, idiopathic thrombocytopenic purpura; H. pylori, Helicobacter pylori. 
responder group, while those who achieved partial remission or no response were defined as the nonresponder group. We evaluated the platelet counts at baseline and 2 and 6 months between the two groups. A schematic diagram of the study is provided in Fig. 1. The study protocol was approved by the Ethics Committee at Seoul National University Bundang Hospital.

\section{Statistical analysis}

All statistical analysis was performed using Predictive Analytics Software for Windows version 20.0 (SPSS Inc., IBM, Chicago, IL, USA). After eradication therapy, to assess the association with the increase platelet count, age, gender, initial platelet count, white blood cell (WBC) count, hemoglobin, absolute neutrophil count (ANC), total follow-up period length, and various other factors such as previous treatment (steroids, immunosuppressive agents, splenectomy, and so forth) were analyzed. Student t-test and analysis of variance test were used to evaluate continuous variables, while Pearson chi-square test and Fisher exact test were used to assess noncontinuous variables. p-values $<0.05$ were defined as statistically significant.

\section{RESULTS}

\section{Patient characteristics}

The patients' baseline characteristics by HPPE, HPNE, and HPN group are shown in Table 1. Between 2003 and 2013, a total of 102 patients (HPPE group, $n=39$; HPNE group, $n=3$; HPN group, $n=60$ ) were diagnosed with chronic ITP. The prevalence of $H$. pylori infection was $41.1 \%(42 / 102)$ in the study population. The average period from the diagnosis of ITP to the date of the last follow-up was $31.5 \pm 29.6$ months in the HPPE group, $31.0 \pm 28.3$ months in the HPNE group and 31.6 \pm 29.0 months in the HPN group ( $p=0.468)$. There were no statistical differences in age, gender distribution, baseline platelet count, WBC count, hemoglobin, ANC, or previous ITP treatment between three groups (Table 1).

\section{Relationship between treatment response and $\boldsymbol{H}$. pylori eradication}

Table 2 compares platelet counts at baseline and 2 and 6 months between the HPPE, HPNE, and HPN groups. Although the baseline platelet count did not differ significantly between the three groups $(p=0.487)$, at 2 months after eradication therapy, the platelet count significantly increased from $43.2 \pm 29.1$ to $104.1 \pm 47.4 \times 10^{3} / \mu \mathrm{L}$ in the HPPE group, from $42.5 \pm 28.1$ to $59.2 \pm 46.1 \times 10^{3} / \mu \mathrm{L}$ in the HPNE group and from $43.1 \pm 28.9$ to $63.7 \pm 47.3 \times 10^{3} / \mu \mathrm{L}$ in the HPN group ( $\mathrm{p}=0.041$ ) (Table 2 ). The platelet count 6 months after eradication therapy was $155.3 \pm 68.7 \times 10^{3} / \mu \mathrm{L}$ in the HPPE group, $79.8 \pm 59.7 \times 10^{3} / \mu \mathrm{L}$ in the HPNE group and $81.2 \pm 62.2 \times 10^{3} / \mu \mathrm{L}$ in the HPN group $(\mathrm{p}=0.036)$ (Table 2). The platelet count significantly increased in the HPPE group compared to those in the HPNE and HPN groups. The recovery effect of the platelets was maintained over the average follow-up period.

Table 1. Baseline Characteristics of the Study Population between the H. pylori-Positive and -Eradicated (HPPE) group, the H. pylori-Positive and -Non-Eradicated (HPNE) Group and the H. pylori-Negative (HPN) Group

\begin{tabular}{|c|c|c|c|c|}
\hline Characteristic & $\begin{array}{l}\text { HPPE group } \\
\quad(\mathrm{n}=39)\end{array}$ & $\begin{array}{l}\text { HPNE group } \\
\qquad(\mathrm{n}=3)\end{array}$ & $\begin{array}{l}\text { HPN group } \\
(\mathrm{n}=60)\end{array}$ & p-value* \\
\hline Age, yr & $52.9 \pm 19.3$ & $53.5 \pm 12.3$ & $53.0 \pm 11.1$ & 0.318 \\
\hline Gender & & & & 0.392 \\
\hline Male & 14/39 (35.9) & $1 / 3(33.3)$ & $27 / 60(45.0)$ & \\
\hline Female & $25 / 39(64.1)$ & $2 / 3(66.7)$ & $33 / 60(55.0)$ & \\
\hline Baseline platelets, $\times 10^{3} / \mu \mathrm{L}$ & $43.2 \pm 29.1$ & $42.5 \pm 28.1$ & $43.1 \pm 28.9$ & 0.487 \\
\hline WBC, $\times 10^{3} / \mu \mathrm{L}$ & $5.4 \pm 2.7$ & $5.9 \pm 1.6$ & $5.6 \pm 1.1$ & 0.695 \\
\hline $\mathrm{Hb}, \mathrm{g} / \mathrm{dL}$ & $13.5 \pm 1.4$ & $13.6 \pm 2.1$ & $13.3 \pm 1.7$ & 0.917 \\
\hline ANC, $\times 10^{3} / \mu \mathrm{L}$ & $3.1 \pm 2.1$ & $3.6 \pm 1.8$ & $3.2 \pm 1.1$ & 0.358 \\
\hline Previous treatment of ITP & & & & 0.972 \\
\hline None & $31 / 39$ (79.5) & $2 / 3(66.7)$ & $48 / 60(80.0)$ & \\
\hline Drugs & $8 / 39(20.5)$ & 1/3 (33.3) & $6 / 60(10.0)$ & \\
\hline Splenectomy & $0 / 39$ & $0 / 3$ & $3 / 60(5.0)$ & \\
\hline Drugs+splenectomy & $0 / 39$ & $0 / 3$ & $3 / 60(5.0)$ & \\
\hline Follow-up periods, mo & $31.5 \pm 29.6$ & $31.0 \pm 28.3$ & $31.6 \pm 29.0$ & 0.468 \\
\hline
\end{tabular}

Data are presented as mean \pm SD or number (\%).

WBC, white blood cell; Hb, hemoglobin; ANC, absolute neutrophil count; ITP, idiopathic thrombocytopenic purpura; ITP drug, prednisolone or immunosuppressive agents.

*ANOVA test. 
Table 2. Comparison of Platelet Counts at 2 and 6 Months Follow-Up between the H. pylori-Positive and -Eradicated (HPPE) Group, the H. pyloriPositive and -Non-Eradicated (HPNE) Group and the H. pylori-Negative (HPN) Group

\begin{tabular}{ccccc}
\hline Platelet count, $\times 10^{3} / \mu \mathrm{L}$ & $\begin{array}{c}\text { HPPE group } \\
(\mathrm{n}=39)\end{array}$ & $\begin{array}{c}\text { HPNE group } \\
(\mathrm{n}=3)\end{array}$ & $\begin{array}{c}\text { HPN group } \\
(\mathrm{n}=60)\end{array}$ & $\mathrm{p}^{- \text {value* }}$ \\
\hline Baseline & $43.2 \pm 29.1$ & $42.5 \pm 28.1$ & $43.1 \pm 28.9$ & 0.487 \\
At 2 months & $104.1 \pm 47.4$ & $59.2 \pm 46.1$ & $63.7 \pm 47.3$ & 0.041 \\
At 6 months & $155.3 \pm 68.7$ & $79.8 \pm 59.7$ & $81.2 \pm 62.2$ & 0.036 \\
\hline
\end{tabular}

Data are presented as $\operatorname{mean}_{ \pm} \mathrm{SD}$.

*ANOVA test.

Table 3. Characteristics of the Study Population between the Responder Group and the Nonresponder Group

\begin{tabular}{lccc}
\hline \multicolumn{1}{c}{ Characteristic } & $\begin{array}{c}\text { Responder } \\
(\mathrm{n}=58)\end{array}$ & $\begin{array}{c}\text { Nonresponder } \\
(\mathrm{n}=44)\end{array}$ & $\mathrm{p}$-value* \\
\hline Age, yr & $52.9 \pm 17.4$ & $53.0 \pm 17.1$ & 0.593 \\
Male sex & $24 / 58(41.3)$ & $18 / 44(40.9)$ & 0.797 \\
Baseline platelet, $\times 10^{3} / \mu \mathrm{L}$ & $40.3 \pm 31.2$ & $40.7 \pm 29.5$ & 0.257 \\
$\mathrm{WBC}, \times 10^{3} / \mu \mathrm{L}$ & $5.3 \pm 2.7$ & $6.2 \pm 1.5$ & 0.151 \\
$\mathrm{Hb}, \mathrm{g} / \mathrm{dL}$ & $13.4 \pm 1.7$ & $13.7 \pm 1.8$ & 0.647 \\
$\mathrm{ANC}, \times 10^{3} / \mu \mathrm{L}$ & $3.3 \pm 2.3$ & $3.5 \pm 1.3$ & 0.779 \\
Previous treatment of ITP & $6 / 58(10.3)$ & $7 / 44(15.9)$ & 0.148 \\
$\quad$ Drugs & $6 / 58(10.3)$ & $4 / 44(9.0)$ & 0.234 \\
$\quad$ Splenectomy & $0 / 58$ & $2 / 44(4.5)$ & 0.348 \\
$\quad$ Drugs+splenectomy & $0 / 58$ & $1 / 44(2.2)$ & 0.465 \\
HP infection (positive) & $39 / 58(67.2)$ & $3 / 44(6.8)$ & 0.356 \\
HP eradication success & $39 / 39(100.0)$ & $0 / 3$ & $<0.001$ \\
Follow-up periods, mo & $25.3 \pm 28.4$ & $26.5 \pm 27.1$ & 0.881 \\
\hline
\end{tabular}

Data are presented as mean \pm SD or number $(\%)$.

WBC, white blood cell; Hb, hemoglobin; ANC, absolute neutrophil count; ITP, idiopathic thrombocytopenic purpura; ITP drug, prednisolone or immunosuppressive agents; HP, Helicobacter pylori.

*Student t-test, Pearson chi-square test, and Fisher exact test.

\section{Comparison of the treatment responder and nonre- sponder groups}

A total of 58 patients had maintained platelet counts $\geq 100 \times 10^{3} / \mu \mathrm{L}$ during the follow-up period of up to 2 months and were categorized into the responder group, while the other 44 patients were categorized into the nonresponder group (Table 3). H. pylori infection was confirmed in 39 patients in the responder group $(39 / 58,67.2 \%)$ and three in the nonresponder group $(3 / 44,6.8 \%)$. The success rate of eradication therapy in the responder group was $100.0 \%$ (39/39), which was significantly higher than that of the nonresponder group $(0 \%$, $0 / 3)(p<0.001)$ (Table 3). Table 4 compares the platelet counts at 2 and 6 months between the responder group and the nonresponder group with the baseline platelet count. Although the baseline platelet count was not significantly different between groups $(\mathrm{p}=0.257)$, it increased from $40.3 \pm 31.2 \times 10^{3} / \mu \mathrm{L}$ to $104.3 \pm 38.7 \times 10^{3} / \mu \mathrm{L}$ at 2 months after eradication therapy in the
Table 4. Comparison of Platelet Counts at 2 and 6 Months Follow-Up between the Responder Group and the Nonresponder Group

\begin{tabular}{cccc}
\hline $\begin{array}{c}\text { Platelet count, } \\
\times 10^{3} / \mu \mathrm{L}\end{array}$ & $\begin{array}{c}\text { Responder } \\
(\mathrm{n}=58)\end{array}$ & $\begin{array}{c}\text { Nonresponder } \\
(\mathrm{n}=44)\end{array}$ & $\mathrm{p}$-value* \\
\hline Baseline & $40.3 \pm 31.2$ & $40.7 \pm 29.5$ & 0.257 \\
At 2 months & $104.3 \pm 38.7$ & $43.1 \pm 24.9$ & 0.037 \\
At 6 months & $152.1 \pm 49.8$ & $51.0 \pm 26.6$ & 0.045 \\
\hline
\end{tabular}

Data are presented as mean \pm SD.

*Student t-test.

responder group and from $40.7 \pm 29.5 \times 10^{3} / \mu \mathrm{L}$ to $43.1 \pm 24.9 \times 10^{3} /$ $\mu \mathrm{L}$ in the nonresponder group $(\mathrm{p}=0.037)$ (Table 4). The platelet count 6 months after eradication therapy was $152.1 \pm 49.8 \times 10^{3} /$ $\mu \mathrm{L}$ in the responder group and $51.0 \pm 26.6 \times 10^{3} / \mu \mathrm{L}$ in the nonresponder group ( $\mathrm{p}=0.045)$ (Table 4).

\section{DISCUSSION}

In this study, the platelet count significantly increased 2 and 6 months after eradication therapy in the $H$. pylori-positive and -eradicated group than those in the $H$. pylori-positive and -non-eradicated group and $H$. pylori-negative groups. Moreover, the success rate of eradication therapy was significantly higher in the responder group than in the nonresponder group. Accordingly, this suggests a relationship between the success of eradication therapy and increase in platelet count. Studies have shown that other factors that affected the response after eradication therapy included the length of time after the ITP diagnosis before eradication therapy was administered and the platelet count before treatment. ${ }^{12,13}$ In this study, the success rate of $H$. pylori eradication therapy was associated only with the increase in platelet count; in particular, in cases of successful $H$. pylori eradication therapy, patients were more likely to show an effective response to treatment than patients without $H$. pylori infection or $H$. pylori eradication therapy failure.

Some studies on the prevalence of $H$. pylori in patients with ITP and the effect of $H$. pylori eradication on disease progress have recently been published. In 1998, Gasbarrini et al. ${ }^{5}$ reported improved platelet counts in eight of 11 patients with autoimmune thrombocytopenia who had $H$. pylori eradication; among them, platelet autoantibodies disappeared from six, in- 
dicating the possibility of a relationship between ITP and H. pylori. Emilia et al. ${ }^{14}$ subsequently showed positive findings in 13 of 30 patients (43.3\%) with ITP; among the 12 cases in which eradication therapy was successful, six (50\%) showed an increased platelet count, suggesting the existence of a relationship between ITP and $H$. pylori. In the present study, the prevalence of $H$. pylori infection was $41.1 \%$ (42/102) in the study population; among the $42 \mathrm{H}$. pylori-positive patients, 39 showed a significant increase in platelet count (39/42, 92.9\%), a finding that is consistent with the report of Emilia et al. ${ }^{14}$

Moreover, in a systemic review of clinical trials of $H$. pylori eradication performed not only in patients with ITP and $H$. pylori but also patients with ITP but not $H$. pylori infection, a greater number of $H$. pylori-positive patients showed an increased platelet count compared to those without H. pylori.15 Specifically, $H$. pylori-negative patients showed an increased platelet count in only $8.8 \%$ of patients, while $H$. pylori-positive patients demonstrated an increase in 51.2\%, a difference with an odds ratio of 14.5 (95\% confidence interval [CI], 4.2 to 83.2). ${ }^{15}$ Additionally, in another meta-analysis of prospective trials, platelet count increases were more common in the $H$. pylori-eradicated group compared to the group in which $H$. pylori eradication failed or was not attempted. ${ }^{16}$ The weighted mean difference (WMD) between the successful and failed eradication groups was 52.2 (95\% CI, 34.3 to 70.1; $<<0.0001$ ), and the WMD between the successful eradication group and that in which eradication was not attempted was 40.8 (95\% CI, 20.9 to $60.3 ; p<0.0001$ ), which shows that the differences were significant.

A large-scale study in Japan involving $207 \mathrm{H}$. pylori-positive patients with ITP reported that platelet counts recovered in 63\% after eradication therapy. ${ }^{17}$ However, other studies showed no platelet recovery in any patient with ITP after successful $H$. pylori eradication therapy. ${ }^{9,18}$ Among the many studies conducted in Japan, Italy, and Spain, 48\% to 73\% of patients with ITP showed an increase in platelet count. ${ }^{5,6,19-22}$ Based on these results, several treatment guidelines recommend $H$. pylori eradication for $H$. pylori-positive patients with ITP..$^{23-26}$

To our knowledge, this is the first study to evaluate the effectiveness of $H$. pylori eradication treatment for increasing platelet counts in patients with chronic ITP in a Korean population. Our study showed that $H$. pylori eradication therapy was related to increasing platelet count and that eradication success affected the increase in platelet counts in patients in Korea with chronic ITP.

In conclusion, to date, $H$. pylori has been believed to be one of the etiological factors of ITP, and eradication therapy is a therapeutic method for managing patients with ITP and coexisting $H$. pylori infection. In particular, in the case of patients with steroid-refractory ITP or who experience relapse and require secondary treatment, the administration of immunosuppressive agents may cause side effects and infection. However, in the case of $H$. pylori eradication therapy, side effects are almost absent, the treatment period is short, and the cost of treatment is low. Accordingly, for patients who require secondary treatment and are $H$. pylori-positive, eradication therapy is thought to be suitable second-line treatment and splenectomy or immunosuppressive agents are considered alternative therapeutic options. In addition, the response is faster when eradication therapy is administered compared to when immunosuppressive agents are administered, and the response is maintained for a relatively long time. In the future, large-scale prospective studies are needed that investigate the exact mechanisms of $H$. pylori in the pathogenesis of ITP and the effectiveness of $H$. pylori eradication therapy in patients with ITP.

\section{CONFLICTS OF INTEREST}

No potential conflict of interest relevant to this article was reported.

\section{REFERENCES}

1. Graham DY. Helicobacter pylori infection in the pathogenesis of duodenal ulcer and gastric cancer: a model. Gastroenterology 1997;113:1983-1991.

2. Pasceri V, Cammarota G, Patti G, et al. Association of virulent Helicobacter pylori strains with ischemic heart disease. Circulation 1998;97:1675-1679.

3. Gasbarrini A, Franceschi F. Autoimmune diseases and Helicobacter pylori infection. Biomed Pharmacother 1999;53:223-226.

4. Annibale B, Lahner E, Bordi C, et al. Role of Helicobacter pylori infection in pernicious anaemia. Dig Liver Dis 2000;32:756-762.

5. Gasbarrini A, Franceschi F, Tartaglione R, Landolfi R, Pola P, Gasbarrini G. Regression of autoimmune thrombocytopenia after eradication of Helicobacter pylori. Lancet 1998;352:878.

6. Kohda K, Kuga T, Kogawa K, et al. Effect of Helicobacter pylori eradication on platelet recovery in Japanese patients with chronic idiopathic thrombocytopenic purpura and secondary autoimmune thrombocytopenic purpura. Br J Haematol 2002;118:584-588.

7. Suzuki T, Matsushima M, Masui A, et al. Effect of Helicobacter pylori eradication in patients with chronic idiopathic thrombocytopenic purpura: a randomized controlled trial. Am J Gastroenterol 2005;100:1265-1270

8. Michel M, Khellaf M, Desforges L, et al. Autoimmune thrombocytopenic Purpura and Helicobacter pylori infection. Arch Intern Med 2002;162:1033-1036.

9. Jarque I, Andreu R, Llopis I, et al. Absence of platelet response after eradication of Helicobacter pylori infection in patients with chronic idiopathic thrombocytopenic purpura. Br J Haematol 2001;115:1002-1003.

10. George JN, Woolf SH, Raskob GE, et al. Idiopathic thrombocytopenic purpura: a practice guideline developed by explicit methods for the American Society of Hematology. Blood 1996;88:3-40. 
11. Rodeghiero F, Stasi R, Gernsheimer T, et al. Standardization of terminology, definitions and outcome criteria in immune thrombocytopenic purpura of adults and children: report from an international working group. Blood 2009;113:2386-2393.

12. Rostami N, Keshtkar-Jahromi M, Rahnavardi M, Keshtkar-Jahromi M, Esfahani FS. Effect of eradication of Helicobacter pylori on platelet recovery in patients with chronic idiopathic thrombocytopenic purpura: a controlled trial. Am J Hematol 2008;83:376-381.

13. Stasi R, Sarpatwari A, Segal JB, et al. Effects of eradication of Helicobacter pylori infection in patients with immune thrombocytopenic purpura: a systematic review. Blood 2009;113:1231-1240.

14. Emilia G, Longo G, Luppi M, et al. Helicobacter pylori eradication can induce platelet recovery in idiopathic thrombocytopenic purpura. Blood 2001;97:812-814.

15. Arnold DM, Bernotas A, Nazi I, et al. Platelet count response to H. pylori treatment in patients with immune thrombocytopenic purpura with and without $\mathrm{H}$. pylori infection: a systematic review. Haematologica 2009;94:850-856.

16. Franchini M, Cruciani M, Mengoli C, Pizzolo G, Veneri D. Effect of Helicobacter pylori eradication on platelet count in idiopathic thrombocytopenic purpura: a systematic review and meta-analysis. J Antimicrob Chemother 2007;60:237-246.

17. Fujimura K, Kuwana M, Kurata Y, et al. Is eradication therapy useful as the first line of treatment in Helicobacter pylori-positive idiopathic thrombocytopenic purpura? Analysis of 207 eradicated chronic ITP cases in Japan. Int J Hematol 2005;81:162-168.

18. Michel M, Cooper N, Jean C, Frissora C, Bussel JB. Does Helicobater pylori initiate or perpetuate immune thrombocytopenic pur- pura? Blood 2004;103:890-896.

19. Takahashi T, Yujiri T, Shinohara K, et al. Molecular mimicry by Helicobacter pylori CagA protein may be involved in the pathogenesis of H. pylori-associated chronic idiopathic thrombocytopenic purpura. Br J Haematol 2004;124:91-96.

20. Veneri D, Franchini M, Gottardi M, et al. Efficacy of Helicobacter pylori eradication in raising platelet count in adult patients with idiopathic thrombocytopenic purpura. Haematologica 2002;87: 1177-1179.

21. Hino M, Yamane T, Park K, et al. Platelet recovery after eradication of Helicobacter pylori in patients with idiopathic thrombocytopenic purpura. Ann Hematol 2003;82:30-32.

22. Ando K, Shimamoto T, Tauchi T, et al. Can eradication therapy for Helicobacter pylori really improve the thrombocytopenia in idiopathic thrombocytopenic purpura? Our experience and a literature review. Int J Hematol 2003;77:239-244.

23. Kim N, Kim JJ, Choe YH, et al. Diagnosis and treatment guidelines for Helicobacter pylori infection in Korea. Korean J Gastroenterol 2009;54:269-278.

24. Malfertheiner P, Megraud F, O'Morain CA, et al. Management of Helicobacter pylori infection: the Maastricht IV/ Florence Consensus Report. Gut 2012;61:646-664.

25. Asaka M, Kato M, Takahashi S, et al. Guidelines for the management of Helicobacter pylori infection in Japan: 2009 revised edition. Helicobacter 2010;15:1-20.

26. Fock KM, Katelaris P, Sugano K, et al. Second Asia-Pacific Consensus Guidelines for Helicobacter pylori infection. J Gastroenterol Hepatol 2009;24:1587-1600. 